\title{
CRIAÇÃO DE VALOR COMPARTILHADO E NEGÓCIOS SOCIAIS: EXPLORANDO RELAÇÕES ENTRE ESTRATÉGIAS E DIMENŚ̃ES
}

\section{CREATING SHARED VALUE AND SOCIAL BUSINESS: EXPLORING RELATIONSHIPS BETWEEN STRATEGIES AND DIMENSIONS}

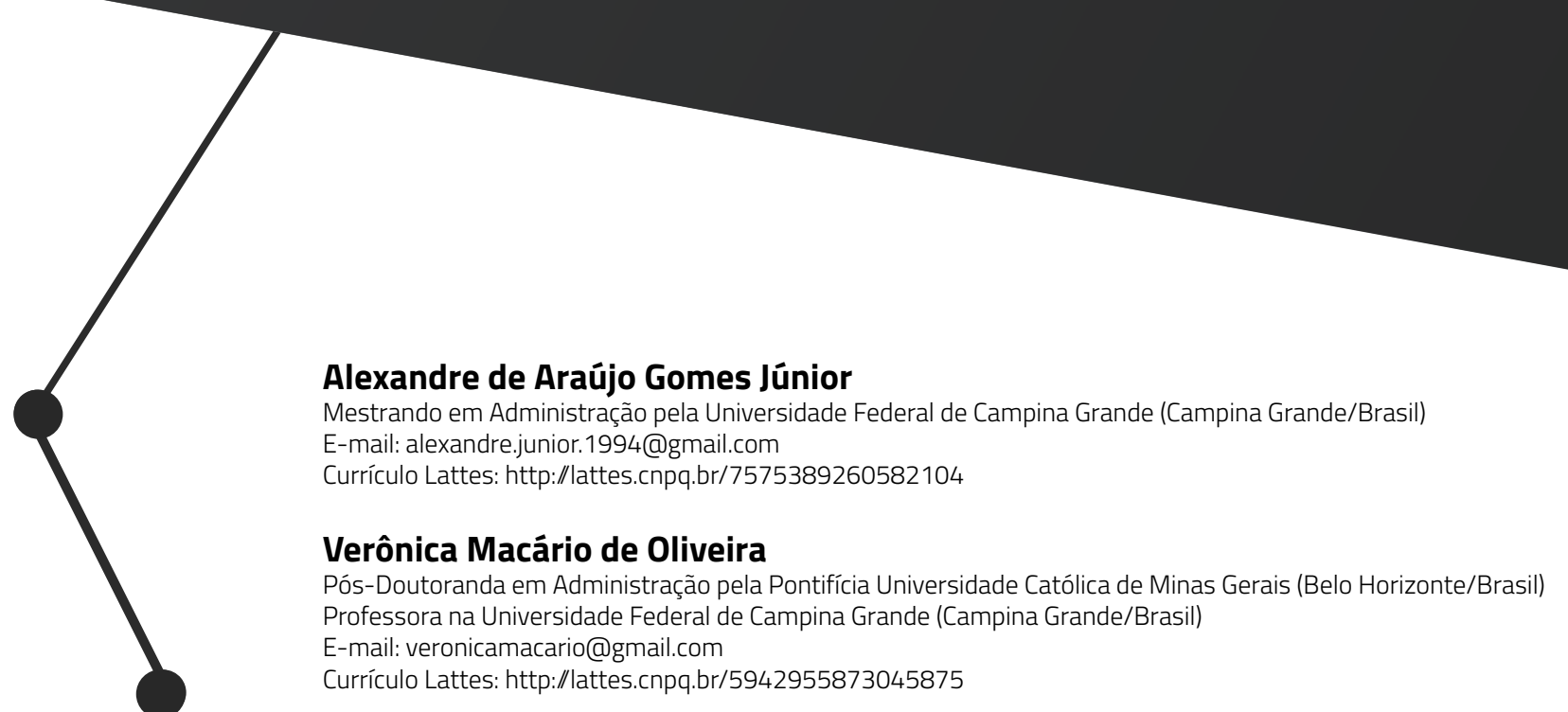

\section{Amanda de Araujo Rodrigues Lira}

MBA em Gestão Empreendedora e Inovação pela Universidade Federal de Campina Grande (Campina Grande/Brasil)

E-mail: rodrigues.ufcg@gmail.com

Currículo Lattes: http://lattes.cnpq.br/2141880345037547

\section{Suzanne Érica Nobrega Correia}

Pós-Doutoranda em Administração pela Pontifícia Universidade Católica de Minas Gerais (Belo Horizonte/Brasil)

Professora na Universidade Federal de Campina Grande (Campina Grande/Brasil)

E-mail: suzanne.enc@gmail.com

Currículo Lattes: http://lattes.cnpq.br/0431849242809370

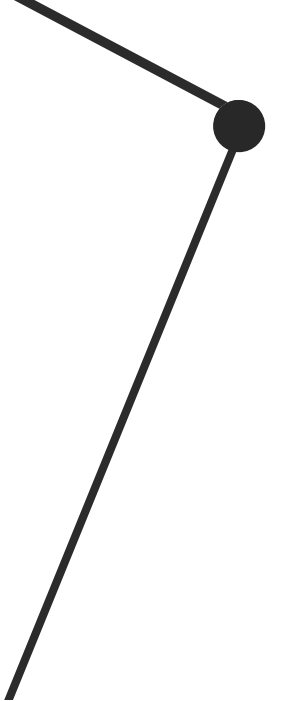

Recebido em: 10 de setembro de 2019

Aprovado em: 21 de novembro de 2019

Sistema de Avaliação: Double Blind Review

RGD | v. 17 |n. 1 | p. 24-48|jan./abr. 2020

DOI: https://doi.org/10.25112/rgd.v17i1.1999 


\section{RESUMO}

O objetivo deste estudo foi analisar como o modelo de negócios sociais se relaciona com as estratégias de criação de valor compartilhado propostas por Porter e Kramer (2011). Para atingi-lo, optou-se pela realização de um estudo de caso múltiplo em dois negócios sociais do setor de educação e tecnologia que atuam no Brasil, que teve como técnicas de coleta de dados a pesquisa documental e a entrevista semiestruturada. Os resultados apontaram que nos modelos de negócios sociais analisados estão implícitas as estratégias de criação de valor compartilhado, pois para atender as necessidades dos mercados em que atuam, os de pessoas de baixa renda e/ou com necessidades especiais, essas organizações precisaram oferecer produtos distintos daqueles que são ofertados em mercados tradicionais. Além disso, esses negócios sociais necessitaram de uma estrutura de operações e competências que contribuíssem para a redução de custos e geração de impacto social; e de um ambiente externo que apoiasse suas atividades para que os benefícios sociais e econômicos pudessem ser disseminados.

Palavras-chave: Negócios sociais. Modelo de negócios. Estratégias de criação de valor compartilhado.

\section{ABSTRACT}

The purpose of this study was to analyze how the social business model relates to the shared value creation strategies proposed by Porter and Kramer (2011). Thus, it was conducting a multiple case study in two social businesses of the education and technology sector operating in Brazil, which had as data collection techniques the documentary research and the semi-structured interview. The results pointed out that the social business models analyzed are implicit in shared value creation strategies because to meet the needs of the markets in which they operate, those of low-income and people with special needs, these organizations had to offer different products those provided in traditional markets. Also, these social businesses required a structure of operations and competencies that contributed to cost reduction and social impact generation; and an external environment that supports their activities to disseminate social and economic benefits.

Keywords: Social Business. Business model. Strategies for creating shared value. 


\section{INTRODUÇÃO}

Os negócios têm um papel indispensável a desempenhar no enfrentamento às questões de ordem social e ambiental que atingem todo o planeta. Eles foram fundamentais para a criação da tecnologia e riqueza que transformou a sociedade no século passado (JACKSON; MICHAELIS, 2003) e, desse modo, se tornam corresponsáveis pelos impactos decorrentes deste processo. As respostas a esses problemas devem ser escaláveis e replicáveis em dimensões globais (JIANOTI, 2015). No entanto, uma noção limitada do capitalismo - baseada na otimização do resultado financeiro de curto prazo (PORTER; KRAMER, 2011) e na convicção de que as preocupações sociais são um empecilho aos negócios, a chamada grande ilusão do trade-off (HART, 2006) — impediu que a prática empresarial explorasse toda sua capacidade para enfrentar os grandes desafios da sociedade (PORTER; KRAMER, 2011).

Contudo, com o aumento das desigualdades sociais, o avanço da degradação do meio ambiente e do esgotamento de recursos naturais (JAHCHAN; COMINI; D'AMARIO, 2016), as discussões sobre os aspectos que permeiam os modelos de negócio têm evoluído e se aprofundado, fazendo seu escopo ultrapassar questões meramente econômicas e incluir, entre outros, aspectos sociais e ambientais (SCHERER, 2014). Percebe-se uma propensão a revisão dos valores das empresas, em particular no que se refere a uma maior consciência sobre o impacto que desejam causar na sociedade e no meio ambiente (COMINI, 2016), estimulada pela persistência e pressão exercidas pelos seus diversos stakeholders. Nesse movimento, a distinção entre as atividades com e sem fins lucrativos se desfaz (PORTER; KRAMER, 2011).

Nesse contexto, emergem novos modelos de negócios baseados em formatos organizacionais híbridos, que procuram atingir objetivos anteriormente tidos como inconciliáveis: a sustentabilidade financeira e a criação valor socioambiental (COMINI, 2016; TEODÓSIO; COMINI, 2012). São negócios que objetivam lucrar ao mesmo tempo que geram impactos sociais e ambientais positivos (IIZUKA et al., 2015), associando um propósito social à lógica econômica e a comportamentos de mercado (WILSON; POST, 2013). Negócios sociais, negócios inclusivos, negócios com impacto social, negócios de impacto, empresas sociais etc. são alguns dos termos utilizados para denominar este tipo de organização (COMINI, 2016; BARKI, 2015; TEODÓSIO; COMINI, 2012). Para fins de padronização, o termo utilizado neste estudo é Negócios Sociais.

Os Negócios Sociais são um fenômeno recente, complexo e multifacetado, cuja compreensão ainda é difícil (BORZAGA et al., 2012), está em fase embrionária (IIZUKA, et al., 2015) e não é homogênea (MOURA, 2011; TEODÓSIO; COMINI, 2012; COMINI, 2016). Assim, existem lacunas que necessitam ser preenchidas com o propósito de contribuir para o desenvolvimento deste campo de estudo contemporâneo (ROSOLEN, et al., 2014). Barki et al., (2015) afirmam que poucas pesquisas têm se dedicado a analisar as estratégias 
e os modelos de negócio que poderiam ser bem mais sucedidos nos negócios sociais. Sugere-se a busca por insights em outras literaturas da Administração para preencher esta lacuna de pesquisa.

Petrini et al., (2016) propuseram um modelo de negócios sociais para melhorar a compreensão das dimensões que o compõe e auxiliar na identificação dos seus elementos. Ademais, os negócios sociais são um tipo distinto de empreendedorismo social (IIZUKA et al., 2015) e que, segundo Porter e Kramer (2011), os empreendedores sociais e as empresas dos países em desenvolvimento, cujos recursos são mais limitados, foram os precursores de um princípio proposto por eles para as empresas em geral, o da criação de valor compartilhado (CVC). A geração de valor econômico está ligada a criação de valor para a sociedade ao buscar enfrentar seus desafios e necessidades, que ocorre por meio de três estratégias: reconceber produtos e mercados, redefinir a produtividade na cadeia de valor, e promover o desenvolvimento de clusters locais.

Nesse contexto, diante da necessidade de se promover avanços teóricos sobre as especificidades da operacionalização dos negócios sociais, o objetivo deste estudo foi analisar como o modelo de negócios sociais se relaciona com as estratégias de criação de valor compartilhado (CVC) propostas por Porter e Kramer (2011). Para isso, foram realizados dois estudos de casos em negócios sociais do setor de educação e tecnologia que atuam no Brasil. Assim, esta pesquisa é de natureza qualitativa e descritiva e as técnicas de coleta de dados foram a pesquisa documental e a entrevista semiestruturada.

Em termos estruturais esse artigo está organizado em cinco seções. Além desta introdução, apresenta-se, na seção seguinte, os fundamentos teóricos dos negócios sociais e das estratégias de criação de valor compartilhado e propõe-se uma aproximação entre os componentes do modelo as estratégias de CVC. Na sequência, são detalhados os procedimentos metodológicos adotados para realização deste estudo. Na quarta seção os resultados são apresentados e discutidos. E, por fim, na quinta seção tem-se as considerações finais dos autores.

\section{NEGÓCIOS SOCIAIS}

A relação conflituosa entre as empresas e a sociedade não é recente (PORTER; KRAMER, 2011), e a gestão desse relacionamento tem sido um dos mais importantes temas das literaturas acadêmica e empresarial (MICHELINI; FIORENTINO, 2012). Desde a Revolução Industrial, as empresas têm operado com base na extração de matéria prima barata, na exploração de mão de obra e na geração de grandes volumes de resíduos e poluição (HART, 2006). Entretanto, atualmente, essas organizações estão cada vez mais preocupadas com os impactos que irão causar na sociedade (BARKI, 2015) e, além disso, descobriram que o seu negócio pode ir muito além da perspectiva econômica (SANTOS; PACHE; BIRKHOLZ, 2015) com 
foco no resultado financeiro. Diante disso, torna-se essencial a existência de modelos de negócios que criem valor ao abordar elementos econômicos, ambientais e sociais, promovam relacionamentos justos entre as partes interessadas e adotem um modelo justo de receita (TATE; BALS, 2018).

Considera-se, portanto, que os limites entre os setores privado, público e sem fins lucrativos precisam ser alterados (HYSA et al., 2018). Nesse cenário, começou a surgir no mundo inteiro um novo formato organizacional híbrido, que busca conciliar os elementos das empresas privadas (como a geração de receita para sustentar suas atividades) e das organizações sem fins lucrativos (geração de impacto socioambiental por meio da redução ou da resolução de determinado problema, ou seja, uma missão social) (SOUZA, 2017; WILSON; POST, 2013). Ele é criado e motivado não apenas pelo raciocínio do retorno econômico-financeiro, mas primordialmente pela geração de benefícios sociais e/ou ambientais (JIANOTI, 2015). Logo, pode ser considerado uma nova opção dentro do sistema capitalista, na qual a ampliação de suas atividades gera benefícios econômicos, sociais e até ambientais (IIZUKA et al., 2015) e, por ser um fenômeno recente, esse tipo de organização tem sido conceituado de diversas formas, apresentando diferentes termos, como negócios sociais, negócios inclusivos, negócios com impacto social, negócios de impacto, empresas sociais etc. (COMINI, 2016; BARKI, 2015; TEODÓSIO; COMINI, 2012).

Assim, o objetivo dos negócios sociais é mostrar que pode resolver problemas sociais, econômicos e ambientais, utilizando o mecanismo empreendedor e o instrumento de lucro, provando no final ser, por padrão, um modelo de negócio sustentável que respeita a abordagem triple bottom line (HYSA et al., 2018). Porém, persiste muita desconfiança em relação a esse tipo de organização híbrida (BARKI, 2015), pois falta uma compreensão coletiva sobre o seu conceito, que procura harmonizar conteúdos que supostamente são inconciliáveis: negócios e impacto social. Essa dificuldade de interpretação homogênea e consensual pode ser explicada por dois motivos: 1) as diferentes maneiras de definir a dimensão social; e 2) as formas diversas de classificar o caráter inovador desse formato híbrido. Isto porque os negócios sociais podem se configurar de formas diversas, ou seja, cada organização pode se posicionar de acordo com seus objetivos e interesses, isto é, existem as que se aproximam mais da lógica de mercado e as que estão mais próximas da lógica social (COMINI, 2016).

Com o propósito de tornar mais clara a compreensão do tema adotada neste estudo, optou-se por adotar a definição elaborada pela Força Tarefa de Finanças Sociais (FTFS), segundo a qual os negócios sociais "são empreendimentos que têm a missão explícita de gerar impacto socioambiental ao mesmo tempo que produzem resultado financeiro positivo de forma sustentável (FTFS, 2015, p.5) ". Sendo assim, mais do que um conceito, os negócios sociais surgem como uma filosofia para repensar e influenciar a forma de se fazer negócios (BARKI, 2015). 


\section{Gestãoe \\ Desenvolvimento}

e-ISSN: 2446-6875

p-ISSN: $1807-5436$

Para elucidar dúvidas sobre a configuração desse novo formato organizacional, Petrini et al., (2016) propuseram um modelo de negócios sociais (Figura 1) composto por cinco dimensões, a saber: (1) rede de parceiros, (2) competências da empresa, (3) proposição de valor, (4) equação de lucro econômico e (5) equação de lucro social.

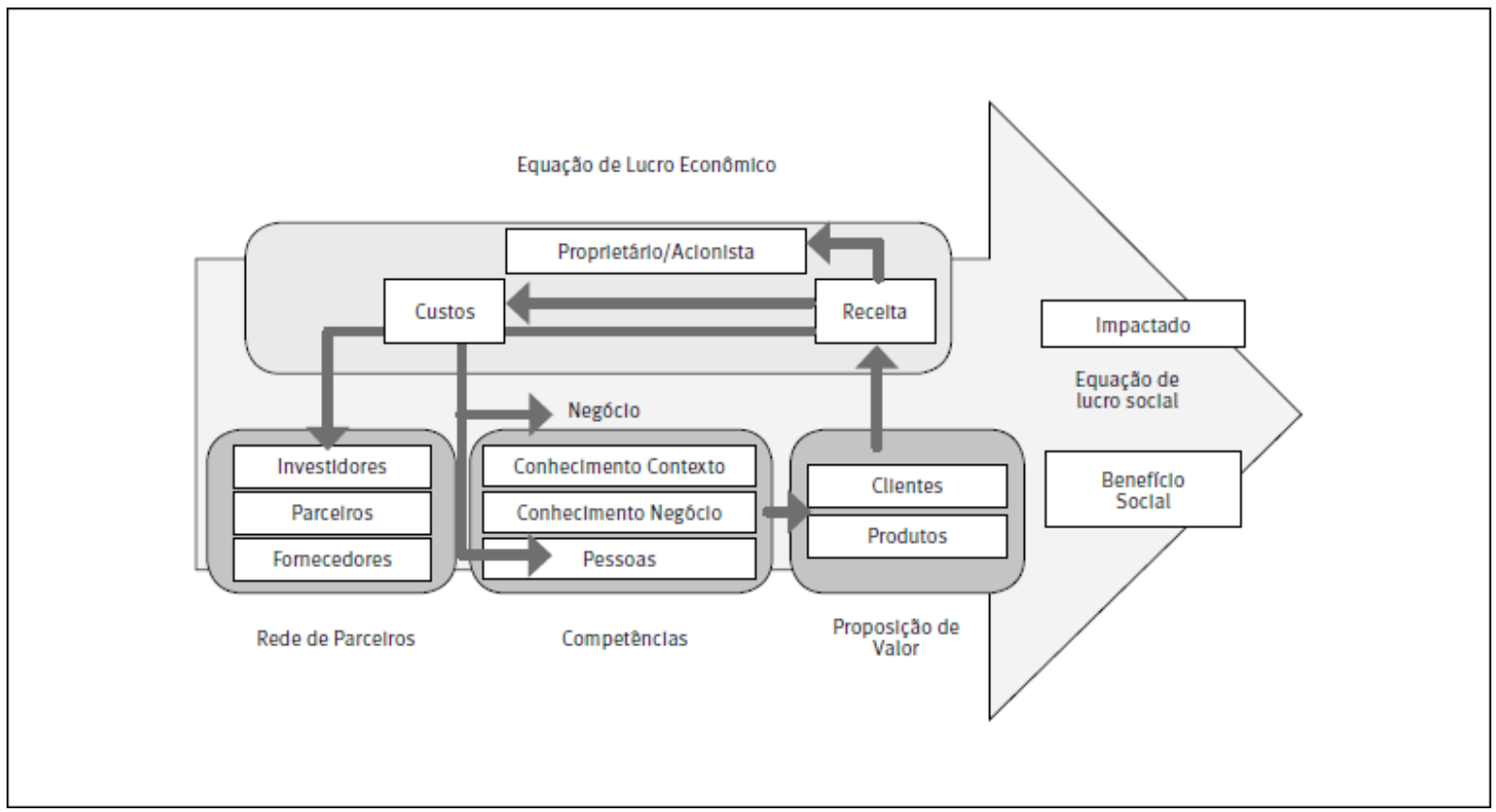

Figura 1 - Modelo de negócios sociais

Fonte: Petrini et al. (2016)

A dimensão "rede de parceiros" é a representação de uma rede de acordos de cooperação feitos entre uma empresa e outras organizações que são fundamentais para que a mesma ofereça e distribua seus produtos de forma eficiente (MICHELINI; FIORENTINO, 2012; OSTERWALDER, PIGNEUR; TUCCI, 2005). No modelo de negócios sociais, essa dimensão compreende os investidores, que são pessoas físicas ou entidades que auxiliam e financiam empreendimentos que produzem impacto social, eles podem ser fundos de investimento, investidores anjos, bancos e o governo; os parceiros, que podem ser associações ou cooperativas que dão apoio ao empreendimento por meio da intermediação entre o negócio e a comunidade que se pretende chegar, também podem ser aceleradoras e incubadoras de negócio; e os fornecedores, que são quem fornece matéria-prima ou mão de obra para a elaboração dos produtos ou serviços. Eles podem ser empresas privadas, agricultores ou produtores locais. (PETRINI et al., 2016). 
A dimensão "competências" diz respeito ao conjunto de conhecimentos, capacidades e habilidades de uma empresa (MICHELINI; FIORENTINO, 2012) que são necessários à execução do seu modelo de negócio (OSTERWALDER, PIGNEUR; TUCCI, 2005). No modelo de negócios sociais, essa dimensão considera as atividades e os recursos chave da organização e é formada pelos seguintes elementos: conhecimento do contexto, que se refere ao nível de informação sobre o local ou comunidade atendida; conhecimento do negócio, que se refere à experiência e ao domínio sobre os processos de produção de bens e/ou prestação de serviços e pessoas, que se refere à dependência do negócio de mão de obra especializada para colocar em prática suas operações (PETRINI et al., 2016).

A "proposição de valor" é definida como um conjunto de benefícios que as empresas oferecem aos clientes para a satisfação de suas necessidades, materializada por uma oferta, que pode ser uma combinação de produtos, serviços, informações e experiências (KOTLER; KELLER, 2012). No modelo de negócios sociais, a proposição de valor é formada pelos clientes, que se refere ao mercado e público alvos que o negócio deseja atender, podendo ser apenas pessoas de baixa renda, de todas as classes econômicas, empresas ou portadores de necessidades especiais, e pelos produtos, que se refere ao produto e/ou serviço que será ofertado pela empresa, se eles serão destinados apenas à população de baixa renda ou serão produzidos por comunidades de baixa renda para outras pessoas de outras classes econômicas. (PETRINI et al., 2016).

A equação de lucro econômico representa a maneira como a empresa ganha dinheiro e o administra (MICHELINI; FIORENTINO, 2012; OSTERWALDER, PIGNEUR; TUCCI, 2005). No modelo de negócios sociais, essa dimensão é formada pelos aspectos financeiros (receitas, que reflete a maneira com que a empresa ganha dinheiro, ou seja, qual a fonte de geração de receita do negócio e custos, os gastos incorridos na operação do negócio) e demonstra relação da organização com os lucros obtidos, isto é, se ele é reinvestido, distribuído ou ambos. (PETRINI et al., 2016). Por fim, a equação de lucro social é a representação do impacto social e/ou ambiental produzido pelo negócio social, o que contempla o beneficiário direto do impacto, que se refere a quem recebe o benefício do negócio, podendo ser os próprios clientes, os moradores da comunidade atendida, pessoas com deficiência ou o meio ambiente; e o benefício social, que representa a melhoria geral que o negócio promove na sociedade, tanto no aspecto social quanto no ambiental (PETRINI et al., 2016).

Em síntese, constata-se que os elementos que compõem as dimensões dos negócios sociais rede de parceiros, competências e proposição de valor - constituem a base de estrutura e operação de uma empresa, que gera as receitas e custos que formam a dimensão da equação de lucro econômico e, também, o impacto social, que é a razão da existência dos negócios sociais, representado pela dimensão de lucro social. (PETRINI et al., 2016). 


\section{Gestãoe \\ Desenvolvimento}

e-ISSN: 2446-6875

p-ISSN: 1807-5436

Além de identificar os elementos que compõem um modelo de negócio social, é importante realizar uma análise de estratégias que podem ser utilizadas com maior êxito por eles (BARKI, et al., 2015).

Ressalta-se que as capacidades empresariais necessárias para abordar questões ecológicas e, particularmente, sociais, são relativamente inexploradas (TATE; BALS, 2018). Porém, as estratégias de criação de valor compartilhado, propostas por Porter e Kramer (2011), se apresentam potencialmente como adequadas no modelo de negócios sociais, porque partem do pressuposto de que a criação de valor compartilhado compreende a geração de valor econômico e de valor social (PORTER; KRAMER, 2011), o que deve estar inerente a ideia de negócios que focam os públicos não atendidos no mercado convencional.

\subsection{CRIAÇÃO DE VALOR COMPARTILHADO}

Porter e Kramer (2011) afirmam que é necessário voltar a unir o sucesso das empresas ao progresso da sociedade, e que isso deve ser feito através da criação de valor compartilhado cuja essência está na geração, simultânea, de valor econômico e social. A criação de valor compartilhado não é responsabilidade social ou filantropia, é um princípio voltado para a atividade principal da empresa, que reconhece que a competitividade de uma empresa e o bem-estar das comunidades que a rodeiam estão intimamente ligados (PORTER; KRAMER, 2011).

Os autores estabelecem três estratégias para se criar valor compartilhado: 1) reconceber produtos e mercados; 2) redefinir a produtividade na cadeia de valor; e 3) promover o desenvolvimento de clusters locais (PORTER; KRAMER, 2011), conforme se apresenta no Figura 2.

\begin{tabular}{|l|l|}
\hline \multicolumn{1}{|c|}{ Estratégia de criação de valor compartilhado } & \multicolumn{1}{c|}{ Descrição } \\
\hline Reconcepção de produtos e mercados & $\begin{array}{l}\text { Consiste em analisar as necessidades não atendidas } \\
\text { dos mercados que podem ser ou estar associadas ao } \\
\text { produto da empresa, e modificá-los para atendê-las. }\end{array}$ \\
\hline Redefinição da produtividade na cadeia de valor & $\begin{array}{l}\text { Baseia-se em modificar a maneira de operar da } \\
\text { empresa e, por meio disso, enfrentar problemas } \\
\text { sociais. }\end{array}$ \\
\hline Promoção do desenvolvimento de clusters locais & $\begin{array}{l}\text { Compreende em corrigir falhas do cluster que afetam } \\
\text { diretamente os custos e a produtividade da empresa. }\end{array}$ \\
\hline
\end{tabular}

Figura 2 - Descrições das estratégias de criação de valor compartilhado Fonte: Elaborado a partir de Porter e Kramer (2011). 
As oportunidades de criação valor compartilhado dependerão de como o negócio e a estratégia da empresa interceptam os problemas sociais (PORTER et al., 2011) e, inevitavelmente, as mais férteis serão aquelas profundamente ligadas ao negócio específico da organização (PORTER; KRAMER, 2011).

As chances de criação valor compartilhado, com base na estratégia de reconcepção de produtos e mercados, mudam de forma constante conforme a tecnologia evolui, as economias se desenvolvem e as prioridades da sociedade se modificam. Diante disso, cabe a empresa analisar continuamente as necessidades da sociedade para descobrir novas oportunidades de diferenciação e reposicionamento em mercados tradicionais e reconhece o potencial de mercados ignorados, como o de baixa renda (PORTER; KRAMER, 2011). E é neste mercado que "as tecnologias de ruptura necessárias para atender aos desafios sociais e ambientais associados ao crescimento econômico poderão ser mais bem incubadas e desenvolvidas (HART, 2006, p. 121)".

A estratégia de redefinição da produtividade na cadeia de valor se dedica a melhoramentos nas operações internas que aperfeiçoam os custos, a qualidade e a produtividade por meio de melhorias no uso de recursos, na logística, nas compras, na distribuição, na produtividade do trabalhador e na localização (PORTER; KRAMER, 2011; PORTER et al., 2011). Dessa forma, a empresa enfrenta problemas sociais por meio de modificações em suas operações, aumentando a sintonia entre o progresso social e a produtividade na cadeia de valor (PORTER; KRAMER, 2011).

Em relação a estratégia de promoção do desenvolvimento de clusters locais, parte-se do princípio de que nenhuma empresa é autônoma, que seu desempenho é afetado por negócios de apoio e pela infraestrutura que a cerca. Ao desenvolver seu clusterpara melhorar sua produtividade e, simultaneamente, preencher lacunas ou corrigir falhas de estrutura ao redor do mesmo, a empresa está criando valor compartilhado. Com isso, a conexão entre o sucesso da organização e o sucesso da comunidade aumenta, pois há geração de emprego, criação de novos negócios e aumento da demanda por serviços auxiliares quando uma empresa cresce (PORTER; KRAMER, 2011).

As três estratégias de criação de valor compartilhado se reforçam mutuamente (PORTER; KRAMER, 2011) e em cada uma delas, a empresa identifica e acompanha resultados sociais e econômicos (PORTER et al., 2011). Para tanto, deve-se buscar valor compartilhado de forma contínua, o que exige uma finalidade social clara, divulgada internamente e externamente e incorporada aos principais processos da organização, como o planejamento estratégico e o orçamento (PFITZER; BOCKSTETTE; STAMP, 2013). Isso faz com que a empresa se concentre no lucro certo, aquele que gera, no lugar de restringir, benefícios para sociedade (PORTER; KRAMER, 2011). Desse modo, observa-se que tais estratégias, apesar de terem sido concebidas com foco em negócios que já operam no mercado convencional, mantém um alinhamento com a emergência dos negócios sociais que também tem como propósito a criação de valor compartilhado. 


\subsection{RELAÇõES ENTRE O MODELO DE NEGÓCIOS SOCIAIS E AS ESTRATÉGIAS DE CRIAÇÃO DE VALOR COMPARTILHADO}

Esta subseção se propõe a explicitar as possiveis relações entre as dimensões que compõem a base do modelo sociais proposto por Petrini et al., (2016) e as estratégias de criação de valor compartilhado propostas por Porter e Kramer (2011). Tais relações são representadas na Figura 3.

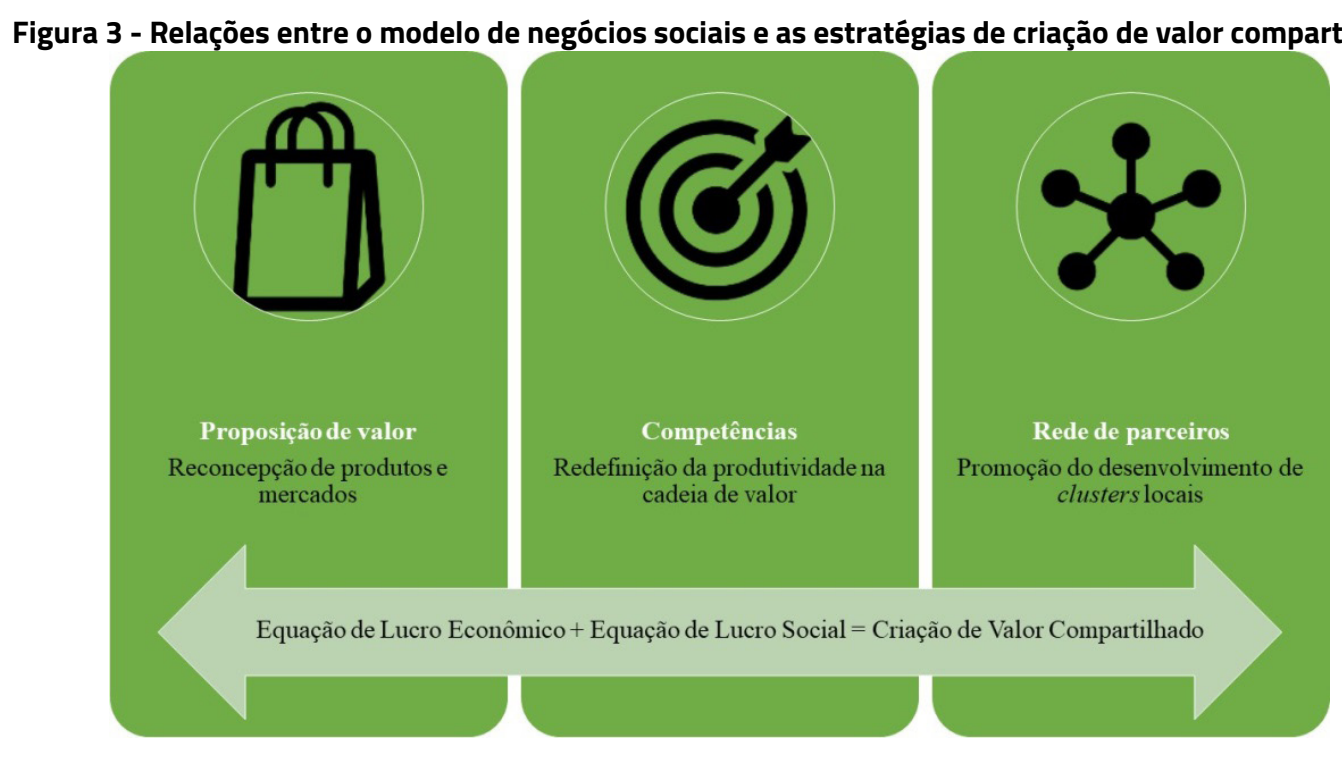

Fonte: Elaborado pelos autores

A proposição de valor nos negócios sociais tem foco no atendimento das necessidades ainda não satisfeitas no mercado tradicional (PETRINI et al., 2016), o que pode está diretamente relacionado com a estratégia de reconcepção de produtos e mercados que visa atender também necessidades não satisfeitas (PORTER; KRAMER, 2011) e, por meio disso, gerar valor social e econômico. Ainda no que tange ao modelo de negócios sociais, a dimensão competências faz parte da base de sustentação das suas operações e se refere a um conjunto de conhecimentos necessários a criação, desenvolvimento e operacionalização da proposta de valor (PETRINI et al., 2016). Constata-se que essa dimensão está associada a estratégia de redefinição da produtividade na cadeia de valor, uma que se destina a otimizar o desempenho operacional da empresa e como resultado, gerar benefícios na sociedade (PORTER; KRAMER, 2011), ou seja, as "competências" são utilizadas no processo de redefinição da produtividade na cadeia de valor para produzir e/ou otimizar impactos sociais e econômicos através das operações de uma empresa. Isso porque a análise da cadeia de valor permite que as empresas entendam as partes de suas operações 
que criam valor e as que não criam (PORTER, 1991), de modo a otimizar a configuração de suas atividades para obter maior produtividade.

A rede de parceiros tem como propósito promover mecanismos de investimentos ou outras ações que dão suporte para o negócio gerar impacto social (PETRINI et al., 2016). Nesse sentido, relaciona-se com a estratégia de desenvolvimento de clusters que é empregada para desenvolver as organizações e a infraestrutura do local onde a empresa está instalada com a finalidade de melhorar a sua produtividade (PORTER; KRAMER, 2011). Considera-se que os clusters podem promover tanto a concorrência como a cooperação e afetar a capacidade de competição de três maneiras: 1) aumentando a produtividade das empresas sediadas na região; 2) indicando a direção e o ritmo da inovação para prover sustentabilidade dos negócios; e 3) estimulando a formação de novas empresas, o que expande e reforça o próprio cluster (OLAVE; AMATO NETO, 2005). Tanto a dimensão rede de parceiros como a estratégia de promoção de desenvolvimento de clusters tem por objetivo se utilizar do ambiente externo para produzir valor social e desenvolver o próprio negócio, gerando valor econômico.

As dimensões de equação de lucro social e equação de lucro econômico do modelo de negócios sociais representam os seus resultados econômicos e sociais, ou seja, os objetivos inerentes às estratégias de criação de valor compartilhado propostas por Porter e Kramer (2011).

\section{PROCEDIMENTOS METOdOLÓGICOS}

O objetivo deste estudo foi analisar como o modelo de negócios sociais se relaciona com as estratégias de criação de valor compartilhado propostas por Porter e Kramer (2011), a partir da realização de um estudo de caso múltiplo, que foi realizado em dois negócios sociais que atuam no Brasil no setor de educação e tecnologia. Portanto, esta é uma pesquisa qualitativa, na qual a coleta de dados, sem avaliação numérica, é utilizada para descobrir ou aprimorar perguntas de pesquisa no processo de interpretação (SAMPIERI; COLADO; LUCIO, 2013).

Quanto aos fins, ela é descritiva, porque procurou especificar propriedades, características e traços importantes do fenômeno que está em análise e explorar as relações teóricas existentes entre os temas abordados (SAMPIERI; COLADO; LUCIO, 2013), ilustrando-as a partir da análise dos dados empíricos. As unidades de análise foram dois negócios sociais do setor de educação e tecnologia, Alpha e Beta (nomes fictícios).

Como técnicas de coleta de dados, foram utilizadas a pesquisa documental e a entrevista semiestruturada. A pesquisa documental foi realizada nos sites de cada um dos negócios sociais e também em notícias que tinham como objeto as organizações estudadas aqui. Nas entrevistas feitas, os sujeitos 
da pesquisa foram um gestor de cada um dos negócios sociais, que são também sócios-proprietários. Eles foram escolhidos de forma intencional, o que segundo Creswell (2010), permite que o pesquisador entenda o problema e a questão de pesquisa. Elas foram executadas de forma não presencial (via Skype), com um roteiro semiestruturado baseado nas literaturas de negócios sociais e das estratégias de criação de valor compartilhado, gravadas por meio do aplicativo MP3 SKYPE RECORDER 4.41 e reproduzidas pelos aplicativos GROOVE MÚSICA (da Microsoft) e o gravador de voz do sistema operacional Android.

Os dados obtidos nas entrevistas foram analisados seguindo os seguintes passos propostos por Creswell (2010) para a análise e interpretação dos dados qualitativos: (1) organização e preparação: na qual as entrevistas foram transcritas, (2) leitura: as entrevistas foram lidas em sua totalidade, (3) codificação: os dados foram organizados de acordo com as categorias de análise apontadas na literatura sobre os dois temas, (4) descrição: os dados sobre as unidades de análise da pesquisa foram descritos, (5) representação: informa como os dados serão representados na pesquisa, e (6) interpretação: consistiu em extrair significado do que foi obtido com as entrevistas, relacionando as estratégias de criação de valor compartilhado com as dimensões do modelo de negócios sociais.

\section{RESULTADOS E DISCUSSÕES}

Esta seção faz a apresentação dos resultados obtidos durante a pesquisa com duas organizações classificadas como negócios sociais, "Alpha" que é uma microempresa de tecnologia que desenvolve e comercializa plataformas virtuais para realizar avaliação cognitiva e pedagógica em crianças com dificuldade de aprendizagem, e "Beta" que é uma microempresa que oferece produtos de base tecnológica (aplicativo e plataforma virtual) para otimização de processos pedagógicos. O propósito é descrever e explorar as relações existentes entre as dimensões dos modelos de negócios sociais investigados e as estratégias de criação de valor compartilhado.

\subsection{A PROPOSIÇÃO DE VALOR E A ESTRATÉGIA DE RECONCEPÇÃO DE PRODUTOS E MERCADOS}

A proposição de valor representa o que é ofertado pela empresa a seu público-alvo. Nos negócios sociais ela visa atender pessoas de baixa renda e/ou portadores de necessidades especiais, ou ainda, ser produzida por esse público para qualquer classe econômica. Para isso, os produtos devem ser distintos dos que são produzidos no mercado tradicionais, tornando-se necessário reconceber produtos e mercados já existentes para adequá-los as necessidades ainda não satisfeitas por eles.

As relações identificadas entre a dimensão "proposição de valor" dos negócios sociais investigados e a estratégia de reconcepção de produtos e mercados são apresentadas na Figura 4. 
Figura 4 - Relações entre a proposição de valor e a estratégia de reconcepção de produtos e mercados

\begin{tabular}{|c|c|c|}
\hline Empresas & $\begin{array}{l}\text { Dimensão } \\
\text { Proposição de Valor }\end{array}$ & $\begin{array}{c}\text { Estratégia } \\
\text { Reconcepção de produtos e mercados }\end{array}$ \\
\hline Alpha & $\begin{array}{l}\text { Produtos de base tecnológica baseados } \\
\text { na neurociência de aprendizagem } \\
\text { direcionado a crianças com dificuldade } \\
\text { de aprendizagem, bem como a escolas, } \\
\text { professores, profissionais liberais e pais } \\
\text { que lidam com esse público-alvo. }\end{array}$ & $\begin{array}{l}\text { Os produtos oferecidos pela escola para estimulação } \\
\text { cognitiva e pedagógica possuíam limites físicos de } \\
\text { atender ao público alvo. Para aumentar a escala da } \\
\text { metodologia utilizada foi desenvolvida uma plataforma } \\
\text { virtual e aplicativos com mesmos usuários e clientes } \\
\text { diferentes }\end{array}$ \\
\hline Beta & $\begin{array}{l}\text { A empresa oferta um aplicativo e } \\
\text { uma plataforma virtual que fornece } \\
\text { ferramentas de apoio para otimizar os } \\
\text { processos pedagógicos e melhorar o } \\
\text { desempenho acadêmico de alunos em } \\
\text { diferentes níveis. }\end{array}$ & $\begin{array}{l}\text { Os produtos inicialmente eram destinados aos alunos } \\
\text { e limitado ao conteúdo de biologia e o conteúdo era } \\
\text { ofertado gratuitamente. Percebeu-se a oportunidade } \\
\text { de direcionar a oferta do produto para as escolas. Para } \\
\text { aumentar a escala da proposição de valor, o produto foi } \\
\text { reconfigurado e houve a definição e um novo segmento } \\
\text { de mercado a ser atendido. }\end{array}$ \\
\hline
\end{tabular}

Fonte: Elaborado pelos autores.

A proposição de valor dos negócios sociais deve ser explicitada como objetivo central de suas operações, declarada em sua missão para evidenciar os impactos sociais e ambientais que poderão ser gerados a partir da reconcepção de produtos e mercados já existentes (PETRINI et al., 2016). Nesse sentido, Alpha surgiu diante da oportunidade de migrar os serviços prestados por uma escola que promove cursos de estimulação cognitiva e pedagógica para crianças e adolescentes e desenvolvê-la tecnologicamente por meio de uma plataforma virtual.

A proposta de valor do negócio social Alpha foi desenvolvida com base em quatro produtos que utilizam uma mesma metodologia, baseada na neurociência da aprendizagem, para a avaliação de crianças com dificuldades de aprendizagem, porém com abordagens diferentes e para atender clientes-alvo e beneficiários distintos, a saber: 1) a crianças de dois a seis anos com produto direcionados a estimulação da aprendizagem; 2) escolas que destinam o uso aos professores de crianças com dificuldades de aprendizagem (de quatro a doze anos), oferece avaliação cognitiva e pedagógica individualizada dos alunos e tutoria para intervenção nas dificuldades de aprendizagem por meio de jogos e testes; 3) profissionais liberais que utilizam a plataforma como ferramenta de trabalho tais como psicólogos, fonoaudiólogos, psicopedagogos e terapeutas ocupacionais, oferecendo avaliação cognitiva e pedagógica individualizada de pacientes de quatro a doze anos e tutoria para intervenção nas dificuldades de aprendizagem por meio jogos e testes e com o auxílio de um assistente virtual; 4) pais ou responsáveis por crianças com 
dificuldades de aprendizagem, que utilizam a plataforma como meio de auxílio à crianças de quatro a doze anos para melhorar seu desempenho cognitivo e pedagógico por meio de avaliações feitas através dos jogos e das atividades.

A entrega de valor do negócio Alpha possui duas formas de acesso aos produtos ofertados: 1) os clientes pagantes através de assinatura, e 2) o acesso gratuito de aplicativo para estimulação cognitiva e da plataforma digital para escolas é oferecida gratuitamente para algumas escolas públicas em decorrência da contratação de assinaturas por profissionais liberais.

Considera-se que um dos fatores impulsionadores para a reconcepção de produtos foi a identificação das necessidades de profissionais da área da saúde, pois o tempo de uma consulta com esses profissionais não possibilita que as crianças utilizem tantos os jogos e realizem tantos os testes para a avaliação cognitiva e pedagógica como nas escolas, em que o tempo que a criança permanece é maior. Outro fator que motivou a reconcepção foi o grau de conhecimento técnico dos profissionais de saúde, um dos fatores chave elencados por Petrini et al., (2016) na definição dos modelos de negócios sociais, que atendem essas crianças com dificuldades de aprendizagem. Assim surgiu a plataforma destinada a profissionais liberais disponibilizando um assistente virtual que direciona o profissional "para que ele possa intervir na deficiência de maneira assertiva", segundo o sócio entrevistado.

Além disso, a mais recente reconcepção de produtos do negócio social Alpha deu origem a plataforma destinada a pais ou responsáveis que "na maioria das vezes não tem conhecimento técnico em relação a dificuldade da criança, mas desejam melhorar e acompanhar o desempenho pedagógico e cognitivo dela" (Entrevistado Alpha). Diante disso, pode-se perceber que os produtos foram reconcebidos visando atender as necessidades de diferentes clientes e observando também as necessidades dos usuários/ beneficiários, ou seja, as crianças com dificuldade de aprendizagem que fazem parte dos públicos-alvo dos negócios sociais relacionados a portadores de necessidades especiais.

Por outro lado, o negócio social Beta surgiu no ano de 2006 sob o formato de site destinado a prévestibulandos da Universidade Federal de Santa Catarina, com o conteúdo de biologia. Posteriormente, a proposta de valor do negócio foi ampliada e foram adicionadas outras disciplinas e mentorias para vestibulares de outros estados. Hoje, Beta oferece um aplicativo e uma plataforma virtual que têm por objetivo fornecer ferramentas de apoio para otimizar os processos pedagógicos e melhorar o desempenho acadêmico de alunos de ensino fundamental II, ensino médio, pré-vestibular, concursos públicos, cursos militares e exame da OAB (Ordem dos Advogados do Brasil), e atua nos mercados B2B (Business to Business) e B2C (Business to Consumer).

A proposição de valor do negócio social Beta é formada por dois produtos: 1) um aplicativo que é disponibilizado que em uma versão gratuita para estudantes de diversos graus de ensino (fundamental, 
médio, concurso e teste da ordem dos advogados do Brasil), e outra paga através de uma assinatura para ter acesso ao conteúdo mais amplo ofertado; e 2) uma plataforma virtual desenvolvida para escolas, na qual professores preparam simulados para seus alunos, os coordenadores podem acompanhar o desempenho discente e os gestores da escola ganham com redução de custos em horas aulas de preparação. A proposição de valor do negócio social Beta foi moldada a partir da constatação da oportunidade de negócio, conforme apontado por Porter e Kramer (2011) e Petrini et al., (2016), por meio da plataforma digital oferecida tanto para alunos quanto para escolas, o que inclui especificamente as escolas públicas, através de financiamento cruzado, ou seja, a partir das assinaturas pagas adquiridas são ofertadas assinaturas gratuitamente para escolas públicas.

Porter e Kramer (2011) afirmam que a estratégia de reconcepção de produtos e mercados abrem possibilidades inéditas para inovação, e isso gera valor compartilhado, ou seja, benefícios tanto para a empresa como para a sociedade. Considera-se que os resultados apresentados nos dois negócios sociais, a partir da reconcepção dos produtos e dos mercados, foram provenientes de inovações nos processos e produtos ofertados com foco sempre nas necessidades dos clientes/usuários. Isto possibilita ampliar o impacto social almejado na definição inicial do que seria a proposição de valor. Além disso, a FTFS (2015) determina que os negócios sociais precisam explicitar, monitorar e reportar as mudanças pretendidas, de modo a delinear de forma concreta e objetiva a lógica e a viabilidade do negócio em gerar impacto. Assim, considera-se que a estratégia de reconcepção de produtos e de mercados na criação de valor compartilhado norteiam e dão suporte a dimensão da proposição de valor dos negócios sociais.

\subsection{COMPETÊNCIAS E A ESTRATÉGIA DE REDEFINIÇÃO DA PRODUTIVIDADE NA CADEIA DE VALOR}

As competências envolvem os conhecimentos, as capacidades e as habilidades presentes em uma empresa, capazes de promover a oferta de um benefício aos seus clientes e que podem diferenciálas das demais no mercado. Essas variáveis podem contribuir significativamente para redefinição da produtividade na cadeia de valor e possibilita obter escala nos impactos gerados. As relações entre a dimensão competências e a produtividade na cadeia de valor nos negócios sociais investigados estão descritas na Figura 5. 


\section{Gestãoe \\ Desenvolvimento}

e-ISSN: 2446-6875

p-ISSN: 1807-5436

Figura 5 - Relações entre as competências e a estratégia de redefinição da produtividade na cadeia de valor

\begin{tabular}{|l|l|l|}
\hline Empresas & \multicolumn{1}{|c|}{$\begin{array}{c}\text { Dimensão } \\
\text { Competências }\end{array}$} & \multicolumn{1}{c|}{$\begin{array}{c}\text { Estratégia } \\
\text { Redefinição da produtividade na cadeia de valor }\end{array}$} \\
\hline Alpha & $\begin{array}{l}\text { Existência de conhecimento de contexto de } \\
\text { crianças com dificuldade de aprendizagem e de } \\
\text { negócio de neuropediatria e devido à natureza } \\
\text { dos serviços ofertados há dependência de } \\
\text { mão de obra especializada. }\end{array}$ & $\begin{array}{l}\text { A cadeia de valor se dedicou a melhoramentos } \\
\text { nos processos de avaliação de crianças com } \\
\text { novo canal de distribuição que ampliou o acesso } \\
\text { aos serviços ofertados. }\end{array}$ \\
\hline \multirow{3}{*}{ Beta } & $\begin{array}{l}\text { Existência preliminar de conhecimento de } \\
\text { contextoeducacionaledenegócio;dependência } \\
\text { de mão de obra especializada envolvida no no } \\
\text { processo de ensino/aprendizagem e novas } \\
\text { tecnologias educacionais. }\end{array}$ & $\begin{array}{l}\text { Buscou-se redefinir a produtividade na cadeia de } \\
\text { valor a partir de melhorias nas operações internas } \\
\text { que aperfeiçoaram os custos de operação, a } \\
\text { qualidade e a produtividade no uso de recursos } \\
\text { tecnológicos e educacionais envolvidos no canal de } \\
\text { distribuição. }\end{array}$ \\
\hline
\end{tabular}

Fonte: Elaborado pelos autores.

Uma das principais competências presentes no negócio social Alpha é o conhecimento do contexto anterior ao estabelecimento do negócio social, em decorrência de um dos seus sócios ser neuropediatra e já trabalhava com uma metodologia própria há cerca de dez anos, em uma clínica e em uma escola, o que também demonstra a existência de conhecimento de negócio. Assim, a metodologia foi incorporada aos produtos ofertados, direcionadas as crianças com dificuldade de aprendizagem. Havia o domínio prévio da maneira de como prestar o serviço e o que mudou foi a forma de disponibilizá-los, de entregar valor para os clientes e para os usuários, pois os serviços passaram a ser oferecidos em plataformas virtuais e aplicativos, o que tem uma relação direta com a produtividade na cadeia de valor, uma vez que propicia a redução dos custos operacionais e aumenta a escalabilidade.

Entretanto, cabe ressaltar que a melhoria na produtividade do negócio depende de mão de obra especializada, pois ele atua em um segmento de interseção entre os setores de educação e saúde, o que exige profissionais com especializados, e os produtos oferecidos em formato digital precisam ser desenvolvidas por profissionais com conhecimento técnico em áreas específicas como computação e design.

Em relação ao negócio social Beta, pode-se afirmar que existia conhecimento do contexto por parte de um dos sócios que é professor e atuou em escolas por mais de vinte anos, de modo que conhecia as necessidades do público-alvo. Além disso, havia conhecimento do negócio que possibilita democratização do acesso à educação, obtido inicialmente através do site com conteúdo de biologia para vestibulares. Assim como no negócio social Alpha, constatou-se a dependência de mão de obra especializada para 
operacionalizar seu modelo de negócios, em decorrência do conteúdo envolvido na oferta dos produtos e dos meios técnicos necessários para desenvolver o aplicativo e a plataforma, o que exige profissionais especializados nas áreas de desenvolvimento de sistemas e design.

Diante dos resultados apresentados nos dois negócios sociais investigados, pode-se constatar que para atender as necessidades dos clientes e redefinir a produtividade na cadeia de valor, as competências relacionadas ao conhecimento de contexto e de negócio foram essenciais para inserir os negócios no ambiente virtual. Para tanto, como apresentado na seção anterior, utilizou-se da estratégia de reconcepção de produtos e mercados visando adequá-los ao público-alvo selecionado e a geração do valor social esperado, o que interferiu diretamente na sua forma de operar em áreas como produção, marketing e distribuição, como explicam Porter e Kramer (2011) ao abordar o processo de criação de valor compartilhado.

Além disso, considera-se, que os negócios sociais investigados possuem um número reduzido de funcionários e a distribuição dos produtos é feita exclusivamente de forma online. Assim, além de gerar valor social decorrentes de seus produtos, a distribuição online reduz também os impactos ambientais devido a minimização do uso de recursos em instalações físicas.

\subsection{REDE DE PARCEIROS E A ESTRATÉGIA DE PROMOÇÃO DO DESENVOLVIMENTO DE CLUSTERS LOCAIS}

A rede de parceiros contempla um conjunto de acordos entres diversas organizações e o negócio social que auxiliam na sua criação e no seu desenvolvimento, incluindo investidores, fornecedores e parceiros (PETRINI et al., 2016). Esses relacionamentos podem contribuir para o desenvolvimento dos clusters dessas organizações (PORTER; KRAMER, 2011), que é definido como um grupo geograficamente concentrado de empresas e instituições interligadas e associadas em um setor específico da economia, ligadas por aspectos comuns e complementares, podendo assumir formatos distintos (FLEURY; FLEURY, 2005). As relações entre a dimensão rede de parceiros e o desenvolvimento de clusters locais identificadas nos negócios sociais estudados estão descritas na Figura 6. 


\section{Gestãoe \\ Desenvolvimento}

e-ISSN: 2446-6875

p-ISSN: $1807-5436$

Figura 6 - Relações entre rede de parceiros e estratégia de promoção do desenvolvimento de clusters locais

\begin{tabular}{|c|c|c|}
\hline Empresas & $\begin{array}{l}\text { Dimensão } \\
\text { Rede de parceiros }\end{array}$ & $\begin{array}{l}\text { Estratégia } \\
\text { Promoção do desenvolvimento de clusters locais }\end{array}$ \\
\hline Alpha & $\begin{array}{l}\text { Investidores de empresas privadas e do } \\
\text { SEBRAE, parceria com a Fundação Parque } \\
\text { Tecnológico da Paraíba (PaqTcPB), Incubadora } \\
\text { Tecnológica de Campina Grande (ITCG), } \\
\text { ARTEMISIA, InovAtiva e START PB (SEBRAE) e } \\
\text { mão de obra especializada é local. }\end{array}$ & $\begin{array}{l}\text { As relações estabelecidas entre as instituições } \\
\text { parceiras fazem parte do ecossistema de } \\
\text { inovação direcionado ao desenvolvimento de } \\
\text { negócios sociais na cidade de Campina Grande- } \\
\text { PB, fortalecendo-o no cenário nacional, atraindo } \\
\text { investidores e impulsionando o desenvolvimento } \\
\text { do cluster local. }\end{array}$ \\
\hline Beta & $\begin{array}{l}\text { O negócio não possui investidores externos, } \\
\text { os parceiros são Incubadora Tecnológica de } \\
\text { Campina Grande (ITCG), a Fundação Parque } \\
\text { Tecnológico da Paraíba (PaqTcPB) e recebeu } \\
\text { o apoio do SEBRAE e da Inovativa Brasil } \\
\text { e o Governo do Estado da Paraíba, e os } \\
\text { fornecedores de mão de obra especializada são } \\
\text { locais. }\end{array}$ & $\begin{array}{l}\text { As instituiç̃ões envolvidas são, em sua maioria, } \\
\text { de origem local e relacionadas tanto ao setor de } \\
\text { inovação quanto de educação. Contribui para o } \\
\text { fortalecimento do ecossistema local de negócios } \\
\text { sociais e para o desenvolvimento da escalabilidade } \\
\text { do negócio. }\end{array}$ \\
\hline
\end{tabular}

Fonte: Elaborado pelos autores

Constata-se que os relacionamentos com os investidores, com a incubadora e a com aceleradora foram essenciais para o desenvolvimento do negócio social Alpha, o que auxiliou na consolidação do seu modelo de negócio. Por outro lado, o negócio social Beta não contou com financiamento de capital de terceiros que apoiasse o início de suas atividades, mas manteve parcerias com a a Incubadora Tecnológica de Campina Grande (ITCG), a Fundação Parque Tecnológico da Paraíba (PaqTcPB) e recebeu o apoio do SEBRAE e da Inovativa Brasil. Além disso, deve-se destacar o apoio que recebeu do Governo do Estado da Paraíba por meio de um acordo de cooperação cujo objeto está relacionado a plataforma desenvolvida por ela que é utilizada na rede pública de ensino do estado.

Nos negócios sociais em análise, as redes de parceiros foram consideradas fatores críticos para o desenvolvimento do negócio em si e para a promoção de desenvolvimento de clusters locais, porém não de modo tradicional, em que uma empresa faz investimentos em outras organizações e/ou na infraestrutura do local instalada (o que acaba melhorando as condições das comunidades que cercam a empresa e gerando impacto social), o que contribui para melhorar seus resultados financeiros. Nos casos analisados 
aqui os impactos sociais positivos partem dos negócios sociais, pois Alpha obteve aporte financeiro a partir de investimentos de capital de terceiros, e ambos os negócios receberam apoio de incubadoras, aceleradoras e outras instituições que fomentam esse tipo organização para a definição e discussão dos seus modelos de gestão, das suas estratégias e das suas metas enquanto negócios sociais, para que os impactos positivos na sociedade fossem potencializados e também os retornos para os próprios negócios. Esses resultados corroboram o estudo de caso múltiplo realizado por De Sousa Lessa et al., (2017), no qual dois negócios sociais foram analisados, e observou-se que eles têm promovido parcerias com governos e empresas para dar escalabilidade a suas inovações e melhorar o impacto social.

Pode-se dizer que os negócios se desenvolveram devido a intervenção e o apoio de outras instituições e, segundo Porter e Kramer (2011), o crescimento de uma empresa tem efeitos multiplicadores pois empregos são gerados em setores de apoio, novos negócios são criados e a demanda por serviços auxiliares aumenta, o que favorece o desenvolvimento do cluster local. Esses apoios fizeram com que os negócios sociais pudessem comercializar seus produtos, que no caso do negócio Alpha, se destinam a melhorar a aprendizagem de crianças; e no caso do negócio Beta, destinam-se a democratizar a educação fazendo com que haja melhorias nas condições educacionais dos locais em que seus produtos alcançam. Assim, entende-se que a relação dos negócios sociais investigados com os demais stakeholders dos seus clusters é uma função fundamental para o desenvolvimento do modelo de negócio desse tipo de organização, uma vez que permite estabelecer estratégias e implementar ações que possibilitem alcançar os objetivos organizacionais pretendidos, que no caso dos negócios sociais são econômicos e sociais.

\subsection{EQUAÇÃO DE LUCRO ECONÔMICO, EQUAÇÃO DE LUCRO SOCIAL E O VALOR COMPARTILHADO}

As dimensões equação de lucro econômico e equação de lucro social representam os resultados produzidos por negócios sociais. A relação entre essas dimensões é o que diferencia os negócios de sociais das empresas tradicionais, uma vez que esse duplo resultado é o que se espera dessas organizações híbridas. As relações entre as dimensões equação de lucro econômico, equação de lucro social e o valor compartilhado dos negócios estudados estão descritas na Figura 7. 


\section{Gestãoe \\ Desenvolvimento}

e-ISSN: 2446-6875

p-ISSN: $1807-5436$

Figura 7 - Relações entre o lucro econômico, o lucro social e o valor compartilhado

\begin{tabular}{|c|c|c|c|}
\hline Empresas & $\begin{array}{c}\text { Dimensão } \\
\text { Lucro econômico }\end{array}$ & $\begin{array}{l}\text { Dimensão } \\
\text { Lucro social }\end{array}$ & Valor compartilhado \\
\hline Alpha & $\begin{array}{l}\text { As receitas advêm da } \\
\text { venda das assinaturas das } \\
\text { plataformas virtuais, os } \\
\text { custos são relacionados a } \\
\text { mão de obra especializada no } \\
\text { desenvolvimento dos produtos } \\
\text { e na manutenção dos canais e } \\
\text { distribuição online, os lucros são } \\
\text { distribuídos entre os sócios e } \\
\text { reinvestidos no negócio. }\end{array}$ & $\begin{array}{l}\text { Os beneficiários são } \\
\text { crianças com dificuldades de } \\
\text { aprendizagem sendo ou não } \\
\text { de baixa renda. E o benefício } \\
\text { social gerado é a melhoria no } \\
\text { desenvolvimento cognitivo } \\
\text { dessas crianças a partir de } \\
\text { métodos focados nas suas } \\
\text { necessidades. }\end{array}$ & $\begin{array}{l}\text { O negócio social consegue } \\
\text { gerar valor compartilhado na } \\
\text { medida em que gera resultados } \\
\text { econômicos positivos } \\
\text { decorrente da comercialização } \\
\text { dos seus produtos e promove } \\
\text { a inclusão educacional e } \\
\text { melhorias nos processos } \\
\text { de ensino/aprendizagem de } \\
\text { crianças com dificuldades de } \\
\text { aprendizagem. }\end{array}$ \\
\hline Beta & $\begin{array}{l}\text { As receitas provêm da venda } \\
\text { das assinaturas do aplicativo } \\
\text { e da plataforma, os custos } \\
\text { são relacionados a mão } \\
\text { de obra especializada no } \\
\text { desenvolvimento dos produtos } \\
\text { e na manutenção dos canais e } \\
\text { distribuição online e os lucros } \\
\text { do negócio são reinvestidos no } \\
\text { negócio. }\end{array}$ & $\begin{array}{l}\text { Os beneficiários são } \\
\text { estudantes de diversos níveis } \\
\text { de ensino, podendo ser de } \\
\text { baixa renda. E o benefício } \\
\text { social é a democratização do } \\
\text { acesso ao ensino. }\end{array}$ & $\begin{array}{l}\text { O negócio social gera } \\
\text { valor compartilhado pois é } \\
\text { sustentável financeiramente e } \\
\text { gera resultados sociais positivos } \\
\text { a partir da democratização de } \\
\text { acesso à educação, por meio de } \\
\text { seus produtos. }\end{array}$ \\
\hline
\end{tabular}

Fonte: Elaborado pelos autores.

No caso do negócio social Alpha, em relação à equação de lucro econômico, as receitas do negócio advêm da venda dos produtos e os lucros obtidos não sofrem restrição de distribuição, ou seja, tanto é distribuído entre os sócios como é reinvestido no próprio negócio. Essa forma de gerir dos lucros é uma perspectiva direcionada para atrair um maior volume de investimentos, uma vez que se entende que é natural que o investidor espere retorno sobre o investimento (PETRINI, et al., 2016) e tem coerência com o modelo de negócio investigado já que um dos principais impulsionadores do seu desenvolvimento inicial foi proveniente do investimento de capital de terceiros.

No que se refere à equação de lucro social do negócio social Alpha, os beneficiários são crianças com dificuldades de aprendizagem que podem ser ou não de baixa renda, e o benefício social gerado pelo negócio é a melhoria no processo de desenvolvimento cognitivo de crianças com dificuldades de 


\section{Gestãoe \\ Desenvolvimento}

e-ISSN: 2446-6875

p-ISSN: $1807-5436$

aprendizagem, beneficiando também escolas, profissionais liberais e pais que lidam com esse públicoalvo. Desse modo, constata-se que o negócio Alpha gera mais de um tipo de impacto social, corroborando com alguns resultados de outros tipos de negócios sociais apontados no estudo de Petrini et al., (2016).

Em relação ao negócio social Beta, no que se refere à equação de lucro econômico as receitas provêm da venda de seus produtos tanto para pessoas físicas como para empresas, estes clientes têm maior participação nas receitas da mesma. Os lucros são reinvestidos na empresa, seguindo a perspectiva defendida por Yunus (2010) de que todos os lucros deveriam ser reinvestidos nos negócios para ampliar o impacto social gerado. Em relação à equação do lucro social, têm-se como beneficiários estudantes de diversos níveis de ensino, e o benefício social produzido é a democratização da educação. Hoje, há 500.000 (quinhentos mil) usuários cadastrados na plataforma, dos quais 130.000 (cento e trinta mil) são alunos da Rede Estadual de Ensino da Paraíba.

Essas duas dimensões constituem os resultados de um negócio social, que são organizações que objetivam atingir resultados financeiros e sociais de forma simultânea. Esses também são os objetivos das estratégias de criação de valor compartilhado, então, pode-se afirmar que a equação de lucro econômico e a equação de lucro social são a representação do valor compartilhado produzido por um negócio social.

Destarte, a Figura 8 objetiva demonstrar a vinculação entre o modelo de negócio social e o processo de criação de valor compartilhado, com base nos casos analisados.

Figura 8: 0 modelo de negócios sociais e o processo de criação de valor compartilhado

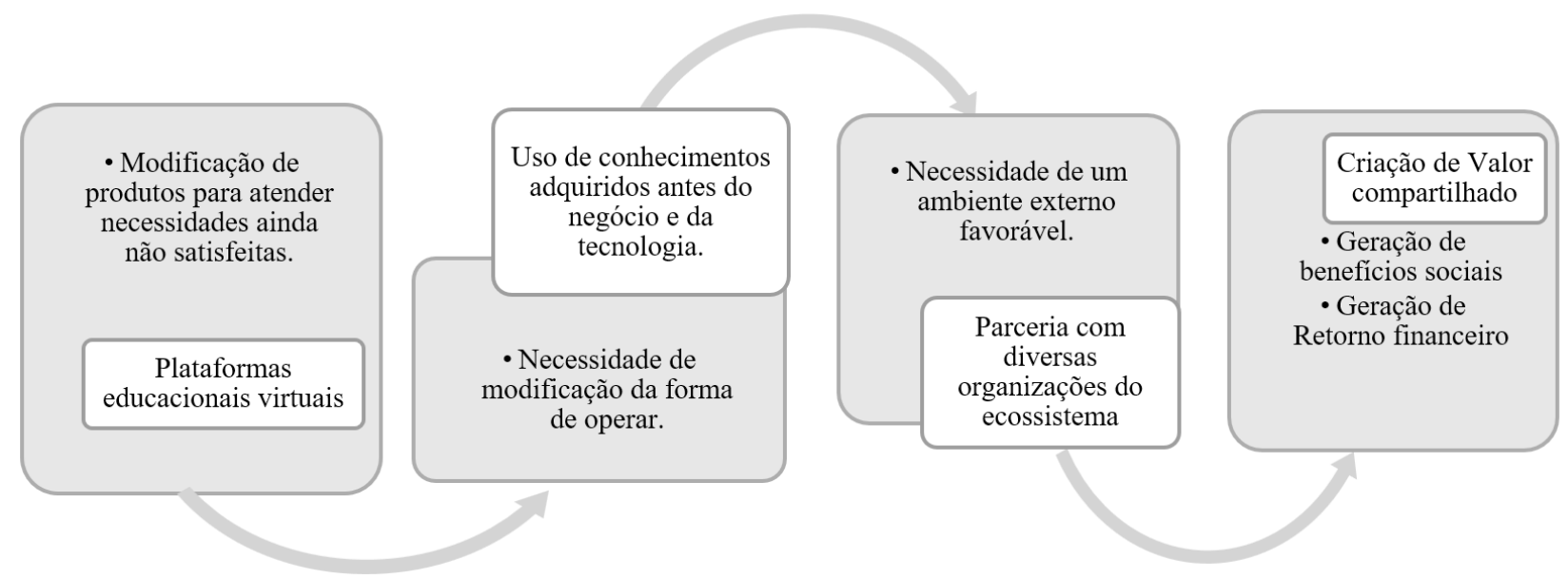

Fonte: Elaborado pelos autores. 
Diante das explanações feitas no decorrer desta seção, pode-se afirmar que o modelo de negócios sociais se relaciona como as estratégias de criação de valor compartilhado nos seguintes aspectos: 1) tanto o modelo como as estratégias buscam resultados sociais e financeiros de forma simultânea; 2) a criação de um negócio social traz consigo a ideia subjacente de reconcepção de produtos e mercados já que esses negócios visam atender necessidades ainda não satisfeitas de pessoas de baixa renda e/ou com necessidades especiais; 3) que para atender esses públicos alvo elas não podem operar da mesma forma de uma empresa tradicional e precisam reduzir seus custos, ou seja, ela tem que modificar a produtividade na sua cadeia de valor, e para isso ela necessita de certas competências organizacionais; e 4) que como qualquer empresa, um ambiente favorável faz com que a produtividade da mesma seja melhorada, e nos caso dos negócios sociais isso significa o aumento de benefícios para a sociedade, que provavelmente terão reflexo no seu cluster. Por fim, as dimensões equação de lucro econômico e equação de lucro social são a representação do resultado esperado que é inerente ao valor compartilhado gerado por um negócio social.

\section{CONSIDERAÇÕES FINAIS}

O objetivo deste estudo foi analisar como o modelo de negócios sociais se relaciona com as estratégias de criação de valor compartilhado propostas por Porter e Kramer (2011), a partir da realização de dois estudos de caso. Nesse sentido é importante destacar como fator importante do processo de criação de valor compartilhado a adequação da proposta de valor à ideia de reconcepção de produto e/ou mercado para atender uma necessidade ainda não satisfeita no mercado tradicional e gerar valor social e financeiro concomitante.

Considera-se, pelo que foi observado nos casos, que os negócios sociais podem enfrentar obstáculos quanto a capacidade da organização em ampliar seus negócios. Porém, se configuram como uma nova alternativa de enfrentamento aos desafios de ordem social e ambiental que atingem a sociedade. Mas, conforme afirmou Barki et al.r (2015) há lacunas de pesquisas que se dedicam a analisar as estratégias que podem ser adotadas em modelos de negócio social para alcançar seus objetivos, de modo que este estudo buscou contribuir com essa lacuna.

Os negócios sociais analisados precisam oferecer produtos que de alguma maneira se distingam dos ofertados por organizações tradicionais, já que eles são intencionalmente projetados para produzir impactos sociais positivos e, não apenas, gerar retornos financeiros. Assim, entende-se, a partir da análise 


\section{Gestãoe \\ Desenvolvimento}

e-ISSN: 2446-6875

p-ISSN: $1807-5436$

feitas nos casos em questão, que os empreendedores que desejam atuar no ambiente dos negócios sociais necessitaram, mesmo que intuitivamente, reconceber produtos e mercados focados em necessidades ainda não satisfeitas de pessoas de baixa renda, portadores de necessidades especiais ou que envolvam questões ambientais.

Cabe destacar que, no que se refere à estratégia de redefinição da produtividade na cadeia de valor quando utilizada em um negócio tradicional gera valor para a sociedade por meio de modificações nas suas operações que objetivam reduzir custos econômicos, isto é, a sociedade é beneficiada na medida em que as empresas reduzem ou previnem impactos negativos. No caso dos negócios sociais observados, a estratégia, além de reduzir ou prevenir possiveis impactos negativos, contribui para tornar mais eficiente o impacto social positivo, por meio da redução de custos, ou seja, os negócios sociais acabam produzindo valor para a sociedade tanto nos meios (suas competências) quanto nos fins (os benefícios sociais) através da escalabilidade.

Em relação à estratégia de promoção de desenvolvimento de clusters locais e a rede de parceiros de um negócio social, pode-se dizer que o conjunto de organizações que auxiliou os negócios sociais analisados pode fazer com que essas organizações produzissem e/ou otimizassem os seus impactos sociais, o que pode ter produzido nos seus respectivos clusters círculos virtuosos de benefícios sociais e econômicos.

Esta pesquisa contribuiu para o avanço do campo de estudos dos negócios sociais na medida em que se pode compreender melhor a operacionalização das estratégias adotadas por organizações desse tipo em contraposição aos modelos de negócios tradicionais. Dessa forma, pode-se entender melhor como os negócios sociais criam valor compartilhado, isto é, como atingem objetivos sociais e econômicos simultaneamente.

Sugere-se, como desdobramentos deste estudo, desenvolverem-se pesquisas que possam analisar a relação do negócio com a comunidade atendida, comparar com os produtos e serviços ofertados por empresas tradicionais e buscar medir os benefícios sociais gerados em decorrência de cada negócio investigado.

\section{REFERÊNCIAS}

BARKI, E. Negócios de impacto: tendência ou modismo? In: GV-executivo, v. 14, n. 1, p. 14-17, 2015.

BARKI, E.; COMINI, G. M.; CUNLIFFE, A.; HART, S.; RAI, S. Social entrepreneurship and social business: retrospective and prospective research. In: Revista de Administração de Empresas, São Paulo, v. 55, n. 4,

p. 380-384, 2015. 


\section{Gestãoe \\ Desenvolvimento}

e-ISSN: 2446-6875

p-ISSN: $1807-5436$

BORZAGA, C.; DEPEDRI, S.; GALERA, G. Interpreting social enterprises. In: Revista de Administração, São Paulo, v. 47, n. 3, p. 398-409, 2012.

COMINI, G. M. Negócios sociais e inovação social: um retrato de experiências brasileiras. Tese de Doutorado. Universidade de São Paulo, 2016.

CRESWELL, J. W. Projeto de pesquisa: métodos qualitativo, quantitativo e misto / John W. Creswell; tradução Magda Lopes; consultoria, supervisão e revisão técnica desta ediç̧ão Dirceu da Silva. - 3. ed. Porto Alegre: Artmed, 2010.

DE SOUZA LESSA, B., DE SOUZA, A. C. A. A., FERREIRA, R. C., \& AGUIAR, İ. C. INNOVATING FOR SOCIAL DEMANDS-A DOUBLE CASE STUDY IN EFFECTIVE SOCIAL ENTERPRISES FROM THE BRAZILIAN SEMIARID. Revista Gestão e Desenvolvimento, v. 14, n. 2, p. 4-18, 2017.

FLEURY, Afonso; FLEURY, Maria Tereza Leme. A arquitetura das redes empresariais como função do domínio de conhecimentos. Redes entre organizações. São Paulo: Atlas, 2005.

FORÇA TAREFA DE FINANÇAS SOCIAIS. Carta de princípios para Negócios de Impacto no Brasil. São Paulo, 2015.

HART, S. L. 0 capitalismo na encruzilhada: as inúmeras oportunidades de negócios na solução dos problemas mais difíceis do mundo. Porto Alegre: Bookman, 2006.

HYSA, Xhimi et al. Social business as a sustainable business model: making capitalism anti-fragile. Sustainability Science, p. 1-12, 2018.

IIZUKA, E. S.; VARELA, C. A.; LARROUDE, E. R. A. Social business dilemmas in Brazil: Rede Asta case. Revista de Administração de Empresas, v. 55, n. 4, p. 385-396, 2015.

JAHCHAN, A. L.; COMINI, G. M.; D'AMARIO, E. Q. Negócios sociais: a percepção, a consciência e o grau de interesse pelo tema para os alunos de graduação em Administração. In: Administração: Ensino e Pesquisa, v. 17, n. 3, p. 537-566, 2016.

JIANOTI, L. Investidores em negócios de impacto. In: SANTANA, A. L. J. de M.; SOUZA L. M. (organ.). Empreendedorismo com foco em negócios sociais. Curitiba, 1. ed., NIST UFPR, p. 31-39, 2015.

KOTLER, P.; KELLER, K. L. Administração de marketing. 13ª ed. São Paulo: Pearson Education do Brasil, 2012.

MICHELINI, L;; FIORENTINO, D. New business models for creating shared value. In: Social Responsibility Journal, v. 8, n. 4, p. 561-577, 2012.

MOURA, A. M. de. Facilitadores e dificultadores na implementação de um negócio inclusivo em três países de diferentes continentes. Tese. Universidade de São Paulo. 2011. 


\section{Gestãoe \\ Desenvolvimento}

e-ISSN: 2446-6875

p-ISSN: $1807-5436$

OSTERWALDER, A.; PIGNEUR, Y.; TUCCI, C. L. Clarifying business models: Origins, present, and future of the concept. In: Communications of the Association for Information Systems, v. 16, n. 1, p. 1-25, 2005.

PETRINI, M.; SCHERER, P.; BACK, L. Modelo de negócios com impacto social. In: Revista de Administração de Empresas, v. 56, n. 2, p. 209-225, 2016.

PORTER, M. E.; HILLS, G.; PFITZER, M.; PATSCHEKE, S.; HAWKINS, E. Measuring shared value: how to unlock value by linking social and business results. FSG, 2011.

PORTER, M. E.; KRAMER, M. R. Criação de valor compartilhado. In: Harvard Business Review, v. 89, n. $1 / 2$, p. 62-77, 2011.

PORTER, Michael E. Towards a dynamic theory of strategy. Strategic management journal, v. 12, n. S2, p. 95-117, 1991.

ROSOLEN, T.; TISCOSKI, G. P.; COMINI, G. M. Empreendedorismo social e negócios sociais: Um estudo bibliométrico da produção nacional e internacional. In: Revista Interdisciplinar de Gestão Social, v. 3, n. 1, p. 85-105, 2014.

SAMPIERI, R. H.; COLLADO, C. F.; LUCIO, M. P. B. Metodologia de pesquisa. 5. ed. Porto Alegre: Penso, 2013.

SANTOS, Filipe; PACHE, Anne-Claire; BIRKHOLZ, Christoph. Making hybrids work: Aligning business models and organizational design for social enterprises. California Management Review, v. 57, n. 3, p. 3658, 2015.

SCHERER, P. C. Entendendo os negócios com impacto social: uma análise dos elementos constituintes do modelo de negócio. Dissertação de Mestrado. Pontifícia Universidade Católica do Rio Grande do Sul, 2014.

TATE, Wendy L.; BALS, Lydia. Achieving shared triple bottom line (TBL) value creation: toward a social resource-based view (SRBV) of the firm. Journal of Business Ethics, v. 152, n. 3, p. 803-826, 2018.

TEODÓSIO, A. S.; COMINI, G. M. Inclusive business and poverty: prospects in the Brazilian context. In: RAUSP - Revista de Administração da Universidade de São Paulo. v. 47, n. 3, p. 410-421, 2012.

WILSON, F.; POST, J. E. Business models for people, planet (\& profits): exploring the phenomena of social business, a market-based approach to social value creation. In: Small Business Economics, v. 40, n. 3, p. 715-737, 2013.

YUNUS, Muhammad. Criando um negócio social: como iniciativas economicamente viáveis podem solucionar os grandes problemas da sociedade. Elsevier, 2010. 